\title{
Ellen Richards e as "Ciências Domésticas":
}

\section{elementos para a compreensão da proposta científica de Economia Doméstica ${ }^{1}$}

\author{
José Carlos do Amaral Júnior \\ Universidade Estadual do Sudoeste da Bahia (UESB) \\ jcamaral1987@gmail.com \\ Ana Elizabeth Santos Alves ${ }^{3}$ \\ Universidade Estadual do Sudoeste da Bahia (UESB) \\ ana alves183@hotmail.com
}

Como citar este artigo: AMARAL JÚNIOR, J. C.; ALVES, A. E. S. "Ellen Richards e as "Ciências Domésticas": elementos para a compreensão da proposta científica de Economia Doméstica", Intelligere, Revista de História Intelectual, n9, pp. 230-251. 2020. Disponível em < http://revistas.usp.br/revistaintelligere>. Acesso em dd/mm/aaaa.

Resumo: Esse artigo pretendeu demonstrar como, longe de demarcar especificamente o surgimento da Economia Doméstica, a proposta de Ellen Richards e de suas companheiras indicou uma tentativa radical de dar status científico à área, aproximando-a da eugenia e promovendo uma reconceituação conservadora no sentido de cientificar os saberes e fazeres do mundo doméstico. Dessa forma, analisando especificamente os elementos de duas das mais importantes obras da autora, "The Cost Of Shelter" (1905) e "Euthenics" (1912), foi possível perceber como a proposta formulada pelas pioneiras do Lake Placid Club buscavam romper com as "artes mecânicas" e se aproximar do método científico das ciências exatas e biológicas, pela via da normatização e higienização dos espaços, sob a égide ideológica da eugenia. Reservadas as pontuais rupturas históricas dessa proposta, o artigo possibilitou perceber como os elementos centrais dessa área permaneceram inalterados por mais de um século, incluindo o modelo de Economia Doméstica implementado no Brasil e cuja extinção no sistema de ensino formal é evento recente.

Palavras-chave: Economia Doméstica, Ciências Domésticas, eugenia, eutenia.

\footnotetext{
${ }^{1} \mathrm{O}$ artigo faz parte do trabalho de pesquisa em andamento "A pedagogia do doméstico: uma memória apreendia da síntese dialética entre a Economia Doméstica e a extensão rural”.

2 Doutor do Programa de Pós-Graduação em Memória: Linguagem e Sociedade pela Universidade Estadual do Sudoeste da Bahia (UESB).

${ }^{3}$ Professora aposentada da Universidade Estadual do Sudoeste da Bahia (UESB).
} 


\section{Ellen Richards and the "Domestic Sciences": elements for nderstanding} the scientific proposal of Home Economics

Abstract: This article intended to demonstrate how, far from specifically marking the emergence of Home Economics, the proposal by Ellen Richards and her companions indicated a radical attempt to give scientific status to the area, bringing it closer to eugenics and promoting a conservative reconceptualization, in order to make the knowledge and practices of the domestic world as a science proposal. Thus, analyzing specifically the elements of two of the author's most important works, "The Cost Of Shelter" (1905) and "Euthenics" (1912), it was possible to see how the proposal formulated by the Lake Placid Club pioneers sought to break with the "Mechanical arts" and to approach the scientific method of exact and biological sciences, through the standardization and hygiene of spaces, under the ideological aegis of eugenics. Reserved for the occasional historical ruptures of this proposal, the article made it possible to see how the central elements of this area remained unchanged for more than a century, including the model of Home Economics implemented in Brazil and whose extinction in the formal education system is a recent event.

Keywords: Home Economics, Domestic Sciences, eugenics, euthenics.

A Economia Doméstica é uma área de formação/campo de conhecimento de origem estadunidense que foi amplamente difundida pelo mundo no final do século XIX e início do século XX. Sua origem remete ao contexto das efervescências sociais que se acentuaram a partir 1840, acompanhando mudanças expressivas nos modos de vida e de produção das sociedades capitalistas, principalmente as europeias e os Estados Unidos da América (EUA). No Brasil, embora iniciativas isoladas de implementação de cursos e disciplinas de Economia Doméstica tenham ocorrido já por volta de 1909, sua popularização ocorreu apenas mais tarde, no final da década de 1940, acompanhando uma intensa tendência de efetivação de uma política agrícola no país: a extensão rural.

É comum demarcar historicamente o surgimento da Economia Doméstica em terras estadunidenses na virada para o século XX como iniciativa de um pequeno grupo de mulheres pertencentes às classes abastadas, que se reuniram em uma série de encontros chamados de Lake Placid Conferences, na cidade de Nova Iorque, a partir de 1899. Lideradas por Ellen 
Richards, primeira mulher a estudar e ingressar no corpo docente do Massachusetts Institute of Technology (MIT), elas fundaram a American Home Economics Association (AHEA) e formularam uma proposta de área científica que denominaram Home Economics'.

Importante destacar, no entanto, que a Economia Doméstica já possuía uma complexa trajetória pregressa nos EUA, que remete à 1841 com a publicação de "A Tratise On Domestic Economy" da reformista social e educacional Catherine Beecher. Sua origem, portanto, remonta a uma série de publicações que, a partir da segunda metade do século XIX, multiplicaram-se na tentativa de aplicar ao ambiente doméstico diversas técnicas e conhecimentos que se desenvolviam em distintas áreas - como a medicina, a química, a construção civil e a produção têxtil. Dessa maneira, a Economia Doméstica teve um surgimento relativamente difuso, efetivando-se inicialmente pelo caráter "manualesco", cuja ocorrência está longe de ser ocasional e reflete um intenso debate estadunidense em torno do preparo das donas-de-casa para um mundo em constantes transformações - debate no qual a abolição tardia da escravidão no país teve importante influência. O tratado de Catherine Beecher (1841) marcou esse campo de discussão, em que eram reivindicadas as habilidades "naturais" da mulher para as atividades domésticas, argumentando sob o discurso moral-cristão-liberal que a educação feminina fosse direcionada para a apreensão dos "mais modernos" conhecimentos relacionados ao lar, seu espaço vocacional.

A Economia Doméstica nos EUA manteve essa característica de projeto de reforma social dispersa por pelo menos duas décadas, quando a promulgação do Morril Act de 1862 criou as condições necessárias para que a proposta fosse institucionalizada. O Morril Act, também conhecido como a "lei de concessão de terras", criou as condições jurídicas necessárias para que fossem implantados os Land-Grant Colleges, instituições de educação que deveriam romper com a tradição estadunidense de formação de profissões de colarinho branco e direcionar um ensino mais prático e aplicável à realidade

\footnotetext{
${ }^{4}$ A tradução do termo para o português é "Economia Doméstica", embora nos EUA exista diferença entre os termos Domestic Economy (utilizado na segunda metade do século XIX) e Home Economics (adotado a partir do século XX).
} 
agrária. Essa reforma educacional, portanto, criou as condições necessárias para que a Economia Doméstica figurasse lado a lado das disciplinas das ciências agrárias e biológicas, integrando o conjunto de "artes mecânicas" que eram a base dos Land-Grant Colleges, fortemente marcados pela prática extensionista que também emergia nesse contexto. Dessa maneira, a Economia Doméstica era integrada à proposta como a "área de intervenção" especificamente destinada às mulheres do campo, sob o amplo e difuso discurso de "melhoria da qualidade de vida".

Foram as instituições desse caráter que efetivaram os primeiros projetos de Economia Doméstica pelos EUA, tradição que seria reproduzida em certa medida no Brasil quase um século mais tarde, com a incorporação do curso majoritariamente em universidades e colégios de demarcado caráter agrário. No entanto, as ações de Ellen Richards e do grupo da AHEA modificaram alguns dos elementos tradicionais da Economia Doméstica que vinha sendo difundida pelos EUA, com destaque para a tentativa de construir uma Ciência Doméstica. Esse artigo pretende demonstrar como, longe de demarcar especificamente o surgimento da Economia Doméstica, a proposta de Richards e de suas companheiras indica, por outro lado, uma tentativa radical de dar status científico à área, aproximando-a da eugenia e promovendo uma reconceituação conservadora no sentido de cientificar os saberes e fazeres do mundo doméstico.

\section{Home Economics: construindo uma "ciência doméstica"}

Muitos autores delimitam que a Economia Doméstica surgiu formalmente no início do século XX enquanto Home Economics pela AHEA, cuja principal representante foi Ellen Richards. Esse argumento de gênese da Economia Doméstica, salvo as devidas contribuições da AHEA para a área, esvazia as ideias fundadoras que se iniciaram cerca de meio século antes e secundariza a importância do Morril Act para a popularização da proposta nos EUA. Marca uma história tradicional focada nos grandes nomes e grandes feitos que, em detrimento de revelar as verdadeiras contingências históricas que levaram a Economia Doméstica a assumir determinado formato na virada do século, imputa sua consolidação a um grupo de "mulheres bem-intencionadas". 
Foi o Morril Act que marcou a ruptura necessária com os primórdios da Economia Doméstica do tratado de Catherine Beecher, que havia logrado pouco êxito em se popularizar nos moldes moralistas-cristãos e liberais propostos pela reformista social. Assim, mesmo que a AHEA - mais tarde renomeada para American Association of Family and Consumers Sciences (AAFCS) reforce a narrativa do surgimento da Economia Doméstica segundo as Lake Placid Conferences, algumas instituições destoam dessa premissa:

At the turn of the 20th century, home economics was a critical pathway into higher education for American women, largely associated with co-educational land grant institutions such as Cornell. From its inception, collegiate home economics was multidisciplinary and integrative with an emphasis on science applied to the real world of the home, families and communities ${ }^{5}$ (Cornell University, 2001, s/p.).

O termo Home Economics é uma atribuição exclusiva ao grupo formado por Ellen Richards e suas colaboradoras. Richards era já famosa à época, não só pelas publicações influentes, mas também por ter sido a primeira mulher a obter uma graduação no MIT. Lopes (1995) demonstra, no entanto, que a presença de Richards no Instituto esteve longe de ser harmoniosa e que, de certa maneira, o interesse dela em construir uma área de conhecimento aplicada que se apropriasse dos conteúdos da química e da engenharia sanitária para o ambiente doméstico pode estar relacionado com a busca de legitimidade entre seus pares, cuja aceitação seria mais provável se Ellen, enquanto mulher, ficasse a cargo de um "braço" da instituição que tivesse conexões específicas com o "mundo feminino".

A primeira das Lake Placid Conferences, proposta de encontros de periodicidade anual, ocorreu em setembro de 1899, em Nova Iorque, e foi descrita em seu documento oficial como o resultado de "[...] um tempo para algumas ações em conjunto daqueles mais interessados na ciência doméstica, ou economia dos lares [...]" (AHEA, 1901, p.1. Tradução nossa). O convite foi enviado pelo Lake Placid Club para aquelas consideradas mulheres interessadas na temática, seguindo com uma lista de assuntos "sugeridos para discussão". O

\footnotetext{
${ }^{5}$ Em tradução livre: "Na virada do século XX, a economia doméstica era um caminho crítico para o ensino superior para as mulheres americanas, em grande parte associado a instituições dos lant-grant co-educacionais, como Cornell. Desde a sua criação, a economia doméstica colegial era multidisciplinar e integradora, com ênfase na ciência aplicada ao mundo real do lar, famílias e comunidades".
} 
contexto de organização das conferências demonstra o recorte de classe em que emergiu a proposta, marcadamente absorvida pelas mulheres de uma burguesia urbana nortista, em contraste com o contexto anterior de uma Economia Doméstica difundida entre as mulheres de estratos de classe mais variado, em contextos agrários sulistas.

No convite enviado para as mulheres que integrariam as conferências, constavam entre os assuntos sugeridos: o interesse em promover um levantamento bibliográfico na área, com recomendações de uso; a intenção de promover um levantamento sobre as experiências em Economia Doméstica que se desenvolveram nos EUA e na Europa; o preparo de uma série de "papers" e "brochures" na área de Ciência Doméstica, especialmente aqueles da área de alimentação e nutrição que seriam difundidos pelo Departamento de Agricultura dos EUA; a intenção de fomentar uma discussão acerca da possibilidade de ampliar a oferta em escolas específicas ou naquelas já em atividades; treinar professoras em Ciências Domésticas; pensar como as ciências domésticas poderiam auxiliar a mulher em seu próprio trabalho; discutir sobre a Ciência Doméstica nos "farmers instititutes"; pensar em um método adequado de cooperação entre as estações experimentais e as escolas de Ciências Domésticas; e pensar em um nome adequado que interpretasse melhor o trabalho executado (American Home Economics Association, 1901).

Estas três últimas questões devem ser melhor analisadas: a intencionalidade de discutir a Economia Doméstica em sua atuação nos institutos de caráter agrícola, que foram instituídos com o Morril Act, e em colocá-la à serviço das estações experimentais - parte fundamental do modelo institucional dos Land-Grant Colleges estadunidenses - demonstra a tentativa de estabelecer uma conexão direta e mais forte com certo modelo institucionalizado de educação que possibilitaria a ampliação e difusão da Economia Doméstica. No documento de 1901 é possível perceber também o uso do termo "domestic science", que aparece pela primeira vez na proximidade da virada do século. Esse é um marco importante, uma vez que toda a trajetória da Economia Doméstica pelo século XX será marcada pela tentativa de

\footnotetext{
${ }^{6}$ Nome também utilizado para designar os Land-Grant Colleges.
} 
estabelecer-se como uma ciência, almejando para si os métodos, instrumentos e rigor das ciências exatas e biológicas - uma certa "emulação" dos campos e áreas tipicamente masculinas (Lopes, 1995).

Sobre a última questão posta, o documento da AHEA (1901) expõe:

\begin{abstract}
After full discussion the name "Home Economics" was agreed on as the title preferable for the whole general subject and it was determined to consider it a distinct section of the general subject of economics, so that it should find a logical place in the college and university course and not be confused with the mere "househould arts" often taught under larger names ${ }^{7}$ (p.4-5).
\end{abstract}

Pode-se perceber que a primeira conferência buscou não apenas estabelecer um nome diferente para a Economia Doméstica, mas que as mulheres presentes preocuparam-se também em promover uma diferenciação do que estavam propondo e do que designaram ser uma categoria mais genérica chamada "artes do lar" - as mesmas artes as quais se referia Catherine Beecher de forma otimista décadas antes. O documento da AHEA demonstra que o objetivo era transformar a Economia Doméstica em uma ciência que pudesse comportar o método científico em seu rigor e ser objeto de estudo nas escolas e universidades. Assim surgiu, efetivamente, a Home Economics, uma versão fortemente institucionalizada da Economia Doméstica com aspiração à disciplina acadêmica e científica.

Nesse período, embora o que viria a ser mais tarde as Ciências Sociais já demonstrasse sinais de seu desenvolvimento, caso da antropologia e da sociologia, poucas foram as obras verdadeiramente influentes e de impacto significativo, com a exceção do marxismo (Hobsbawm, 2018a). A Economia Doméstica surgiu nesse contexto, enquanto uma proposta que incorporou os avanços das áreas biológicas, principalmente do darwinismo, e alguns elementos das fracas ciências sociais da época (Simão, 2016; Lopes, 1995). Mas, "apesar de tudo, mesmo entre os livre-pensadores, uma nostalgia pela religião permaneceu" (Hobsbawm, 2018a, p.278). O que exemplifica o destaque central dado pelos elementos do cristianismo e seu consequente conjunto de preceitos

\footnotetext{
${ }^{7}$ Em tradução livre: “Após discussão completa, o nome 'Home Economics' foi acordado como o título preferível para o objeto em geral e foi determinado a considerá-lo uma seção distinta do assunto geral da economia, de modo que ele deve encontrar um lugar lógico na faculdade e curso universitário e não ser confundido com as meras 'artes domésticas' ensinadas frequentemente sob uma variedade de nomes.
} 
moralistas que se sucederam nos materiais e discursos da Economia Doméstica pela segunda metade do século XIX.

No entanto, a partir de 1875, justamente onde parece haver uma guinada da Economia Doméstica a outros rumos, é preciso considerar mudanças sociais importantes que ajudam a compreender o fenômeno. O fim do século XIX era compreendido como “o fim de um longo século" que, contrastando com as intensas conturbações das revoluções de suas primeiras décadas, findou-se sob a emergência da Belle Époque (Hobsbawm, 2018a). A economia modificava-se como decorrente tanto do desenvolvimento industrial da Europa, como do progresso experimentado na América do Norte, marcando domínios muito mais amplos do que a Era do Capital havia registrado (Hobsbawm, 2018b). Estava se consolidando a fase imperial do capitalismo, modo de produção que começou a se expandir em formas sem precedentes e cujos resultados imediatos apresentaram-se com uma sensação generalizada de progresso e bem-estar para todos (Op. cit.).

Ainda que essa sensação fosse apenas ilusória em muitos aspectos, o contexto geral acabou resultando em melhores condições para os trabalhadores que conseguiram aumentos de salário reais e maiores facilidades em sua organização (Gruner, 2019). O progresso econômico e tecnológico, portanto, marcou o desenvolvimento de diversas áreas, da economia à legislação trabalhista, passando pelo desenvolvimento das ciências e surgimento de uma "cultura de massa".

É nesse intenso contexto social e político que nos parece situar uma importante mudança da proposta da Economia Doméstica. Acompanhando as efervescentes transformações à época, da estética à tecnologia, seu anseio em tornar-se uma ciência, parte do ensino regular e acadêmico, afastando-se do cunho moralista e generalista que assumiu em meados do século XIX, reflete uma virada de século que foi intensamente marcada pela crença otimista no progresso técnico e científico. Por isso, observamos na extensa pauta da primeira Lake Placid Conference uma preocupação recorrente em estabelecer as diretrizes gerais para essa "nova proposta" - que se divorciava da proposta 
original, marcada por elementos de outra ordem, e se estruturava como "um campo distinto da economia"s.

Uma breve consulta ao acervo de publicações da área disponibilizado pelo projeto Home Economics Archive: Research and Tradition (HEART) da Cornell University permite perceber uma intensa concentração em áreas mais técnicas no início do século XX, como nutrição e técnica dietética, por exemplo, acompanhadas daquelas como decoração e moda. O incremento expressivo das publicações se deu pela forte influência do desenvolvimento estético, sobretudo na área da arquitetura e do design de moda, reflexo direto da Belle Époque (Hobsbawm, 2018b; Gruner, 2019). As publicações da área de Vestuário e Têxteis também foram influenciadas pelo desenvolvimento tecnológico aplicado à indústria têxtil e o aumento da variedade de produtos dessa natureza para o consumidor final. Por sua vez, o aumento das publicações da área de Técnica Dietética, Alimentação e Nutrição refletem o avanço da biologia, da medicina, da agricultura, da engenharia sanitária e da química. Importante lembrar que Ellen Richards era integrante do Departamento de Engenharia e Química Sanitária do MIT e que, originalmente, a proposta de Home Economics orbitava principalmente em torno desses conteúdos (Lopes, 1995). Além disso, a aproximação da proposta formulada nas Lake Placid Conferences se apropriou da concepção de eutenia, fortemente defendida por Ellen Richards e que, em grandes partes, explica as diretrizes gerais da Economia Doméstica no início do século XX.

Para compreendermos melhor os principais elementos envolvidos nessa empreitada, analisaremos, portanto, duas obras específicas que auxiliam a remontar a Economia Doméstica em sua fase Home Economics do início do século XX - e assim sua proposta de "conversão" ao conhecimento científico. São elas: "The Cost Of Shelter" (1905) e "Euthenics" (1912), ambas de Ellen Richards.

\footnotetext{
${ }^{8}$ Segundo relato da AHEA (1901).
} 


\section{Ellen Richards: eutenia, eugenia e ciência doméstica}

De origem humilde do estado de Massachusetts, nos EUA, Ellen Richards foi a primeira e por muito tempo também a única mulher a frequentar o MIT (Heggestad, 2005). Embora diversos documentos demonstrem que sua entrada no Instituto não foi harmoniosa - como o fato dela não possuir inicialmente uma matrícula regular - sem dúvidas sua trajetória na instituição foi fundamental para que os elementos em torno da Economia Doméstica materializada na Home Economics surgissem (Lopes, 1995).

O contexto social e político do início do século $\mathrm{XX}$ fez emergir, portanto, uma proposta diferente de institucionalização da Economia Doméstica, cujos elementos centrais passaram a ser a constituição de uma disciplina científica, uma profissão intervencionista e a consolidação de uma Ciência Doméstica.

Por isso se justifica a escolha das duas obras aqui analisadas: pelo caráter generalista, normativo e técnico com o que se apresentam enquanto constituintes de uma proposta da Home Economics do início do século XX. A primeira das obras, "The Cost Of Shelter" (1905), foi publicada no contexto eufórico da realização das Lake Placid Conferences, representando o reflexo da Belle Époque e também da emergência da Home Economics. Não por acaso, sua narrativa é permeada pela supremacia do "conhecimento técnico" no melhor estilo de "quebra das tradições" que a proposta de Home Economics assumiu. A segunda, "Euthenics" (1912), publicada alguns anos mais tarde, contextualiza a consolidação da AHEA e os planos iniciais de ampla difusão da Economia Doméstica em seu formato de Ciências Domésticas - ilustrando também as amplas contradições que essa proposta passaria a carregar e reproduzir.

Como a produção científica reflete os traços de uma sociedade (Japiassu, 1975), toda a construção em torno do que se pretendia ser uma Ciência Doméstica estava ancorada nos pressupostos científicos hegemônicos do início do século. Assim, a Economia Doméstica passaria a almejar a adoção de uma suposta neutralidade, de métodos específicos das ciências exatas e

${ }^{9}$ O termo foi empregado por Lopes (1995) para descrever as estratégias de intervenção da Economia Doméstica. 
biológicas e iria aderir à normatização dos espaços e vidas como o princípio de sua prática, legislando um afastamento ideológico de seu objeto. Conforme também argumenta Japiassu (1975), "as ciências da educação, na medida em que tentam eliminar as ideologias, para se tornarem científicas, são produtoras de ideologias e de sistemas valorativos" (p.25). A Economia Doméstica, portanto, seguiu tal caminho. Não era, vale ressaltar, um caminho isolado, visto que todas as ciências humanas e sociais da época, sempre que puderam, incorporaram os métodos científicos aceitos e utilizados nas ciências exatas e biológicas (Hobsbawm, 2018b).

Em "The Cost Of Shelter" Ellen Richards introduz a obra com uma nota explicando que a unidade doméstica ${ }^{10}$ existe por uma razão específica, perpassando em todas as possibilidades o modelo de uma aliança entre dois ou mais indivíduos, seja para se protegerem contra o mundo externo ou para se beneficiarem mutuamente. O livro é escrito em oito capítulos, sem uma divisão clara entre conteúdos morais e aqueles de ordem técnica, conforme era padrão percebido nas obras da área no século XIX.

$\mathrm{Na}$ introdução, Richards situa o leitor sobre sua abordagem ao considerar a casa como sinônimo de "lar", o refúgio responsável por unir a família e por fundar a sociedade. Percebe-se a prevalência de um tom narrativo romântico, cujo contraste com a insistência política de Beecher ou com a objetividade pragmática da maioria das autoras da área do século XIX é notável. É importante, no entanto, não se deixar enganar: a autora possui a pretensão narrativa de explicar tanto os aspectos afetivo-emocionais quanto os sociológicos a partir de como as pessoas se organizavam em seu cotidiano doméstico, no mais explícito estilo de defesa que o "ambiente influencia unilateralmente o indivíduo". Sua intencionalidade, mesmo que de início soe extremamente romantizada e pautada em uma pretensa alusão da casa como espaço dos bons afetos, é a de relacionar o ambiente doméstico bem planejado e gerido com a imagem de uma família saudável e, consequentemente, com a de uma sociedade promissora.

${ }^{10}$ Household. 
O saudosismo evocado por Richards tem também um contraste específico: situar o leitor frente às mudanças aceleradas percebidas no estilo de vida e na dinâmica da vida doméstica estadunidense. A autora descreve que as formas de cotidiano típicas do passado, de um país agrário e com unidades domésticas que se organizavam em torno das atividades artesanais e da subsistência, davam lugar a um novo doméstico:

The very essence of that life was the making of things, the preparation for winter while it was yet summer, the furnishing of the bridal chest years before marriage. Fancy a bride to-day wearing or using in the house anything five years old! There are no more pioneer and colonial communities on this continent. Railroads and steamboats and electric power have made this rural life a thing of the past ${ }^{11}$ (Richards, 1905, s/p.).

O fio condutor de "The Cost..." é um mundo industrializado cujas condições de mudanças constantes se apresentam como ameaças direcionadas às familias, sobretudo aos jovens casais que são considerados "novas famílias". Richards defende um ponto de vista a partir do qual o ambiente determina as condições gerais de vida e, portanto, a casa, em sua perspectiva, seria a principal condição do sucesso ou fracasso de uma família e de seus membros.

Importante destacar que Richards fala especificamente de um contraste entre um jovem do campo com um jovem urbano, cujo desinteresse desse último pela construção e pela manutenção de itens básicos de seu cotidiano como suas residências - é uma marca vista como extremamente negativa e que se prolongaria sobre todos os aspectos de sua vida. Apesar de sempre mencioná-los enquanto "young people" é claro seu desígnio ao casal urbano dirigindo-se especificamente à mulher. E aqui, ressalta um argumento constante em sua obra e nas publicações que podem ser vistas na mesma época: a sensação de total despreparo das mulheres para lidar com a vida doméstica "moderna". O texto perpassa uma certa nostalgia em que a vida do "jovem casal do campo", imbuído em outro cotidiano e organização da vida doméstica, é solapada pela industrialização e urbanização, fenômeno intenso nos EUA à época. Richards apresenta a marca de um discurso extremamente

\footnotetext{
${ }^{11}$ Em tradução livre: "A própria essência daquela vida era a produção de coisas, a preparação para o inverno, enquanto ainda era verão, o fornecimento do enxoval anos antes do casamento. Imagine uma noiva vestir ou usar na casa qualquer coisa de cinco anos atrás! Não há mais comunidades pioneiras e coloniais neste continente. Estradas de ferro, barcos a vapor e energia elétrica tornaram essa vida rural uma coisa do passado".
} 
urbano, visto que seu cenário de discussão era tangenciado por uma Nova Iorque efervescente.

O objeto de estudo proposto fica então explícito: auxiliar as jovens famílias a compreender e lidar com os constantes desafios financeiros de manter seus lares. Richards introduz o tema de um ponto de vista predominantemente econômico, argumentando que as condições de uma vida urbana modificadas nas últimas décadas são sentidas na degradação de diversas áreas do cotidiano. A autora apresenta que:

While the socialist may take the ground that salaries must be raised to keep pace with the rise in living expenses, the student of social ethics-Euthenics, or the science of better living-may well ask a consideration of the topic from another standpoint. Is this increased cost resulting in higher efficiency? Are the people growing more healthy, wellfavored, well-proportioned, stronger, happier? If not, then is there not a fallacy in the common idea that more money spent means a fuller life? ${ }^{12}$ (Op. cit.).

Dessa maneira, o seu entendimento é de que a Home Economics deveria ocupar-se da Euthenics, uma ciência cujo objetivo deveria ser proporcionar uma vida melhor pelo controle do ambiente em que os sujeitos vivem e dos recursos que demandam. Assim, convida jovens para se apropriarem dos conceitos necessários para as casas e famílias do século XX, que já demandavam outra complexidade.

Um dos temas recorrentes em "The Cost..." é o custo financeiro de manutenção de uma casa e dos serviços e necessidades domésticas, justificando o título dado a obra. Mesmo que o tema apareça em muitas obras da área do século XIX, na abordagem de Richards ele é não somente central, mas também possui muitos elementos incorporados das ciências econômicas desenvolvidas na virada do século.

\footnotetext{
12 Em tradução livre: "Enquanto o socialista pode tomar a posição de que os salários devem ser aumentados para acompanhar o aumento das despesas de subsistência, o estudante de ética social - Eutênica, ou a ciência de uma vida melhor - pode muito bem fazer uma consideração sobre o tópico sob outro ponto de vista. Esse aumento de custo resulta em maior eficiência? As pessoas estão se tornando mais saudáveis, favorecidas, bem proporcionadas, mais fortes, mais felizes? Se não, então não há uma falácia na ideia comum de que mais dinheiro gasto significa uma vida mais plena?"
} 
O consumo crescente, a industrialização e urbanização em uma velocidade não experimentadas antes e as mudanças sociais decorrentes da virada do século se apresentavam também como ameaças constantes:

From the Atlantic to the Pacific, from Maine to Texas, comes the same dull and sullen roar of domestic unrest. Lack of faithful service is causing the abandonment of the family home, and the fear of the obstacles in the way of establishing new ones threatens the whole social fabric ${ }^{13}$ (Richards, 1905, s/p.).

O tom utilizado por Richards é alarmante em quase todo o livro. A autora chama a atenção para o desenvolvimento do setor de serviços, a introdução das máquinas nas fábricas que modificaram as formas de trabalho do século anterior e como esse "progresso" auxiliou na degradação do trabalho doméstico, visto como exaustivo e de baixo valor. A “era da máquina” seria, portanto, extremamente negativa na medida em que banalizaria um conjunto de valores sobre os quais se sustentavam a construção de um ambiente doméstico saudável. Esses "novos tempos" demandavam novas atitudes.

Todas as mudanças ocorridas nos modos de produção desde cerca de 1875 são, de certa maneira, refletidos no livro. Richards reforça o fim da predominância da subsistência, a separação entre as casas e as manufaturas, o desenvolvimento do setor de serviços e produtos. Assim, completa seu cenário descritivo formulado desde a primeira página de "The Cost...". Diante desse cenário, era necessário preparar um conjunto de especialistas capazes de aplicar o que havia de mais moderno em termos científicos nos lares estadunidenses. Seria necessário trazer para esses lares em caos e decadência os conhecimentos aprimorados da biologia, da medicina, da química, da nutrição, da economia e da indústria. Segundo Richards (1905):

We need to educate house experts, home advisers, those who know how to examine a house not only while it is empty but while it is throbbing with the life of the family. This adviser must be, for many years at least, able to suggest practical methods of overcoming structural defects (more difficult than fresh construction), as well as of modifying personal prejudices.

\footnotetext{
13 Em tradução livre: "Do Atlântico ao Pacífico, do Maine ao Texas, vem o mesmo rugido monótono e sombrio da inquietação doméstica. A falta de serviço confiável está causando o abandono da casa da família, e o medo dos obstáculos no caminho estabelecem novas ameaças a todo o tecido social".
} 
These house experts will, I think, be women of the broadest education, scientific and social. They will have not only a certain amount of medical knowledge, but also the tact and enthusiasm of the missionary which will bring them as friends and benefactors to the despairing mother and the discouraged householder ${ }^{14}$ (s/p.).

Essas experts atuariam no replanejamento de cozinhas, na sanitização dos lares, na formulação de cardápios adequados, no ajuste dos custos domésticos. É possível notar, portanto, a defesa da predominância da intervenção especialista em detrimento da dona de casa que se aperfeiçoava para seu benefício próprio. No entanto, o que parece ser apenas a emergência de um discurso de supremacia do método científico em detrimento dos componentes morais, esconde na verdade uma orientação ideológica importante.

Para compreender melhor o lugar desse conhecimento técnicocientífico na Economia Doméstica proposta por Ellen Richards, é necessário analisar o segundo livro, "Euthenics", publicado em 1912. Se em "The Cost..." o termo Euthenics aparece apenas designando uma melhoria das condições de vida - ou um aprimoramento do homem - pelas melhorias promovidas no ambiente, na obra posterior as conexões do termo com a eugenia ficam esclarecidas. Na introdução do livro, Richards (1912) faz o seguinte paralelo:

The betterment of living conditions, through conscious endeavor, for the purpose of securing efficient human beings, is what the author means by Euthenics [...] Euthenics precedes eugenics, developing better men now, and thus inevitably creating a better race of men in the future. Euthenics is the term proposed for the preliminary science on which Eugenics must be based ${ }^{15}$ (p.viii-ix).

\footnotetext{
14 Em tradução livre: "Precisamos educar especialistas em casa, consultores domésticos, aqueles que sabem examinar uma casa não apenas enquanto ela está vazia, mas enquanto está pulsando com a vida da família. Este consultor deve ser, pelo menos por muitos anos, capaz de sugerir métodos práticos de superação de defeitos estruturais (mais difíceis do que construções novas), bem como de modificar preconceitos pessoais.

Essas especialistas da casa serão, penso eu, mulheres da educação mais ampla, científica e social. Eles terão não apenas uma certa quantidade de conhecimento médico, mas também o tato e entusiasmo da missionária que os levará como amigos e benfeitores para a mãe desesperada e para o desanimado chefe de família".

${ }^{15}$ Em tradução livre: "A melhoria das condições de vida, através do esforço consciente, com o propósito de assegurar seres humanos eficientes, é o que o autor entende por Eutênica [...] Eutênica precede a eugenia, desenvolvendo homens melhores agora, e assim inevitavelmente criando uma raça melhor de homens no futuro. Eutênica é o termo proposto para a ciência preliminar na qual a eugenia deve se basear".
} 
Assim, se compreende que a proposta de eutenia de Richards possuía estreita relação com a eugenia defendida por muitos estudiosos e ideólogos do início do século XX, sendo apresentara pela autora como uma "etapa precedente" de um projeto eugenista de nação. A eugenia deve ser compreendida no contexto das mudanças das últimas décadas do século XIX e do desenvolvimento de certas linhas de pensamento científico, conforme destacamos anteriormente. Hobsbawm (2018b) demonstra como na Era dos Impérios o darwinismo influenciou sobremaneira diversas áreas do pensamento, principalmente as ciências sociais que se consolidavam a partir do século XIX, tendo grande conotação política-ideológica. A eugenia é, portanto, resultado desse contexto de pensamento, cujos elementos remetem à Teoria Pangenética de transmissão dos caracteres de Darwin unida a modelos matemáticos para explicar a diferenciação entre as classes, ideia originalmente desenvolvida por Francis Galton em 1869 (Gioppo, 1996). Ainda segundo essa autora, a eugenia se apresentou como forte influência nas primeiras décadas do século XX para intervenções públicas e teóricas, sobretudo nos contextos urbanos e industriais, difundindo-se sobre o preceito da higiene mesmo que a Teoria Pangenética tenha sido pouco reverberada a partir de 1920:

\footnotetext{
A higienização foi o principal argumento para iniciar esta disciplinarização, que pretendia mudar hábitos e moldar o operário para o seu espaço de trabalho - enfim, criar uma nova mentalidade, A higienização, ou higiene, foi o sinônimo, o termo substitutivo encontrado para a eugenia, criada por Galton na Inglaterra (p.169).
}

Esse talvez seja o argumento mais significativo das obras de Richards aqui analisadas. Primeiro, porque demonstra como a Economia Doméstica do final do século XIX e início do século XX esteve próxima de certas correntes de pensamento que iriam fundamentar intervenções específicas e inclusive posições políticas extremas. Segundo, porque esse discurso aparece no curso do desenvolvimento da Economia Doméstica apenas no contexto da virada do século e sob forte influência de certos paradigmas científicos. Paradigmas que, conforme demonstra Hobsbawm (2018b), estavam longe de abranger apenas alguns setores:

[...] É possível demonstrar que as vinculações entre genética e eugenia eram estreitas no período 1900-1914 e que, tanto na GrãBretanha como nos EUA, as figuras de proa da ciência estavam 
associadas ao movimento, embora antes de 1914, pelo menos na Alemanha e nos EUA, a demarcação entre ciência e pseudociência racista não fosse nada clara (p.388-389).

Terceiro, porque esse discurso, ao que parece, iria permanecer na Economia Doméstica nas décadas seguintes, em formas mais brandas tais como "promover melhores condições de vida" e "melhorar a qualidade de vida das famílias", mas segundo um conjunto de procedimentos e técnicas muito pouco diferenciadas daquilo que era percebido no início do século na proposta de Richards. Esses elementos demonstram como a pretensão de neutralidade científica da Economia Doméstica constitui, na verdade, uma certa "desfiguração ideológica", nos termos de Japiassu (1975), uma vez que tentou incorporar certos valores de um grupo enquanto proposições cientificamente estabelecidas e universais.

Nesses termos, Richards defende em "Euthenics" uma intervenção planejada que esteja ancorada em três pressupostos básicos: (1) A engenharia sanitária; (2) a educação; e (3) a relação entre educação e ciência para a vida. Segundo a autora, os avanços da engenharia sanitária colocariam à disposição conhecimentos e leis capazes de, uma vez levados aos lares e famílias, promover mudanças de hábitos e comportamentos que, em conjunto, acabariam resultando na "eugenia", entendida por ela como a melhoria da raça de forma geral.

Focando em como as principais doenças da época assolavam a sociedade - como a tuberculose, a febre tifóide e a malária - a autora argumentava a favor de como a aplicação desses conhecimentos sanitários poderiam promover uma higienização capaz de melhorar a sociedade. Nesse livro, dirigindo-se especificamente às mulheres, Richards (1912) destaca: "To the women of America has come an opportunity to put their education, their power of detailed work, and any initiative they may possess at the service of the State"16 (p.11).

Todo o desenvolvimento de "Euthenics", portanto, está construído em relacionar essa missão dada as mulheres na prática da educação para a

\footnotetext{
${ }^{16}$ Em tradução livre: "Para as mulheres da América, surgiu a oportunidade de colocar sua educação, seu poder de trabalho detalhado e qualquer iniciativa que possuam a serviço do Estado".
} 
higienização e sanitização dos lares e famílias, perpassando o cuidado com as crianças e enfermos, a vida em comunidade e as prerrogativas do Estado nessa relação. Outro ponto de destaque presente no livro diz respeito ao enfoque que Richards atribui à educação da mulher rural nestes princípios da eutenia. Segundo a autora, o Governo dos EUA atribuiu - provavelmente referindo-se ao Morril Act e à criação dos Land-Grant Colleges - a devida importância a essas mulheres ao permitir que suas demandas de vida cotidiana fossem abrangidas pelos cursos ofertados pelas instituições educativas. Para a autora, diferente das mulheres urbanas, a família está praticamente "à mercê" dos conhecimentos da mulher no meio rural, justificando nesse caso uma necessidade ainda maior de intervenção e de difusão dos saberes que buscava consolidar.

Se "The Cost..." se apresenta mais como um estudo de base sociológica, "Euthenics" é sem sombra de dúvidas uma proposta de ambição científica que pretende ser mais formulada, ousada, politicamente mais circunscrita e com um plano de intervenção mais bem delimitado. As bases da Home Economics, portanto, estão bem representadas nesse segundo livro. Considerando que Ellen Richards foi o nome mais influente da Economia Doméstica no início do século XX, é bastante perceptível que a proposta que apresentou foi o fio condutor das práticas e sistematizações da área nesse período pelo mundo. Sua estreita relação com a eugenia nos ajuda a compreender como a Economia Doméstica do início do século XX tentou superar a concepção moralista de seus primórdios inclinando-se na tentativa de se estabelecer enquanto uma ciência - mesmo que esse movimento tenha como princípio conceitos pseudocientíficos, não tão distantes dos aspectos morais e ideológicos das pioneiras do século XIX. Ainda que a defesa de "Euthenics" pareça diluir-se nas décadas que se sucederam às Guerras Mundiais, o discurso fundamentado por Ellen Richards iria se reverberar por toda a existência da Economia Doméstica - incluindo aqui o formato específico em que chegou ao Brasil e cuja existência prevaleceu até a segunda década dos anos 2000. 


\section{Desdobramentos}

Compreender a influência do pensamento de Ellen Richards auxilia a apreender os principais elementos que marcaram historicamente o modelo de Economia Doméstica que foi importado para diversos países do mundo, incluindo o Brasil com sua adoção "tardia" de uma "Ciência Doméstica". Três elementos de ruptura vão marcar esse distanciamento histórico - entre as duas obras aqui analisadas e as propostas que se desdobraram mundo afora embora a constância da proposta de Home Economics seja mesmo o aspecto mais significativo.

Em primeiro lugar, é preciso considerar que a proposta da eutenia como projeto científico fundador das Ciências Domésticas passou a ser menos explícita da década de 1920 em diante. Arriscamos duas explicações para esse processo: primeiro, pelo caráter extremista que a eugenia assumiu no Partido Social-Nacionalista dos Trabalhadores Alemães na II Guerra Mundial. Segundo, porque a tendência geral das correntes eugenistas foi a de se incorporarem à perspectivas higienistas de forma mais ampla ${ }^{17}$.

Em segundo lugar, apareceu gradativamente na Economia Doméstica da primeira metade do século XX uma constante incorporação do taylorismofordismo aos seus princípios técnicos. $O$ fordismo surgiu enquanto aplicação dos princípios tayloristas por volta de 1908, e representou uma verdadeira revolução na produção em massa ${ }^{18}$. No entanto, mais do que uma forma de gestão do tempo e da produção, o fordismo só pode realizar-se plenamente enquanto incorporado a um determinado modo de vida, de forma total ${ }^{19}$. Assim, a Economia Doméstica integrou esse movimento e, no seu projeto de se constituir enquanto disciplina científica, buscou aplicar os princípios tayloristas-fordistas em todas as suas subáreas, da gestão financeira ao desenho de móveis e cozinhas planejadas. $\mathrm{Na}$ medida em que avançava nessa incorporação, a Economia Doméstica acentuava a sua missão de "quebra das

\footnotetext{
${ }^{17}$ Como demonstra Gioppo (1996).

${ }^{18}$ Harvey (2008).

${ }^{19}$ Gramsci (2001).
} 
tradições", acreditando se realizar enquanto ciência na medida em que tornava mais normatizada e racionalizada a vida doméstica e o cotidiano doméstico.

O advento das tecnologias domésticas nesta época auxilia a intensificar esse processo, dando maior caráter de complexidade às tarefas domésticas, ampliando o debate sobre o despreparo das mulheres para lidar com tais atividades e reforçando uma analogia das casas com as fábricas e indústrias. Esse movimento significou nos EUA, uma verdadeira ruptura tecnológica nas vidas domésticas, uma vez que "as mulheres americanas, num país onde os empregados já eram escassos, há muito pleiteavam - e começavam a conseguir - a transformação tecnológica, e racionalizadora, do trabalho doméstico" (Hobsbawm, 2018b, p.331).

Por último, o contexto específico dos EUA acabou orientando a Economia Doméstica para duas frentes distintas: maior presença nos colégios de caráter agrário, os Land-Grant Colleges, para preparar mulheres do campo na incorporação de novos hábitos e costumes; e uma modificação geral dos hábitos populacionais, principalmente aqueles relacionados à economia de recursos e adaptações alimentares, assuntos necessários nos períodos de Guerra. Uma ampla literatura foi fomentada nestes períodos, indicando que a Economia Doméstica encontrou uma dupla capilaridade em formatos formais e não formais de educação, realizando-se majoritariamente pelo projeto preconizado por Ellen Richards e suas companheiras da Lake Placid Conference.

A partir daí consolidou-se um formato mais ou menos padrão da Economia Doméstica que seria exportado para os demais países. Essa exportação, de fato, não seguiu um fluxo específico. Apesar da literatura e dos estudos históricos sobre a área na primeira metade do século XX serem escassos, sabe-se que a Economia Doméstica foi implementada no Brasil sob alguns formatos diversos ainda nas décadas de 1910 e 1920 (Oliveira, 2006). Mas uma inversão importante aconteceu por volta da década de 1940/1950 nos EUA: a Economia Doméstica, ao que tudo indica, parece ter estagnado nesse período, passando em seguida por um lento declínio de popularidade. Conforme trechos de um documento da Cornell University explicitam: 
But by the late 1950s and the early 1960s, broad changes in American women's economics and social roles made collegiate education in home economics seem 'old fashioned', an image that did not do justice to its rich history ${ }^{20}$ (s/p.).

Justamente nesse contexto, enquanto a Economia Doméstica dos EUA encontrava dificuldades e caminhava para uma profunda crise que culminaria na sua extinção, foi que o modelo da Home Economics estadunidense passou a ser difundido no Brasil. Assim, um projeto de "Ciências Domésticas" foi trazido ao Brasil já em caráter obsoleto, tendo relativa importância nas décadas de 1950-1960 para implantação da extensão rural no país. A partir daí malgrado um relativo sucesso em se manter academicamente, todos os cursos superiores de Economia Doméstica foram oficialmente extintos em 2016, ressaltando o caráter recente em que prevaleceu uma área de formação cuja origem parece, nos dias atuais, extremamente anacrônica.

Além disso, ainda com espaços sócio ocupacionais ativos pelo país, com considerável destaque para as agências de extensão rural que ainda empregam parte dos profissionais de Economia Doméstica no Brasil, a análise da gênese dessa proposta de "Ciência Doméstica" aponta para a necessidade de entender a atualidade do projeto higienista-eugenista de Richards, suas reverberações e suas influências atuais em um modelo de intervenção doméstica.

\section{Referências bibliográficas}

AMERICAN HOME ECONOMICS ASSOCIATION. Lake Placid Conference proceedings: Volume 1-3. 1901.

BEECHER, C. E. A tratise on Domestic Economy - for the use of young ladies at home and school. New York: Harpers \& Brothers, 1841.

CORNELL UNIVERSITY. What was Home Economics? 2001. Disponível em: http://rmc.library.cornell.edu/homeEc/masterlabel.html. Acesso em 31 maio 2019.

GIOPPO, C. Eugenia: higiene como estratégia de segregação. Educar, v. 12, p. 167-180, 1996.

${ }^{20}$ Em tradução livre: "Mas no final da década de 1950 e início da década de 1960, amplas mudanças na economia e nos papeis sociais das mulheres americanas fizeram com que a educação universitária em economia doméstica parecesse "antiquada", uma imagem que não fazia jus à sua rica história". 
GRAMSCI, A. Americanismo e Fordismo. In: Maquiavel, a Política e o Estado Moderno. 8. ed. Rio de Janeiro: Civilização Brasileira, 1991.

GRUNER, C. História, economia, política e cultura no século XIX. Curitiba, PR: Intersaberes, 2019.

HARVEY, D. A Condição Pós-Moderna - uma pesquisa sobre as origens da mudança cultural. 17. ed. São Paulo: Edições Loyola, 2008.

HEGGESTAD, M. What is Home Economics? Mann Library, 2005.

HOBSBAWN, E. A era do capital (1848-1875). 28ª ed. Rio de Janeiro: Paz e Terra, 2018a.

paz e Terra, 2018b.

A era dos impérios (1875-1914). 25ª ed. Rio de Janeiro:

JAPIASSU, H. O mito da neutralidade científica. Rio de Janeiro: Imago Editora Ltda, 1975.

LOPES, M. F. O Sorriso da Paineira: construção de gênero em uma Universidade Rural. Tese (Doutorado em Antropologia Social) - Universidade Federal do Rio de Janeiro, Rio de Janeiro, 1995.

OLIVEIRA, A. C. M. Economia Doméstica: origem, desenvolvimento e campo de atuação profissional. Vértices, v. 8, n. 1, 2006.

RICHARDS, E. H. Euthenics - the science of controllabel enviroment. A plea forbetter living conditions as a first step toward higher human efficiency. 2. ed. Boston, Massachusetts: Witcomb \& Barrows, 1912.

Of Technology, 1905.

The cost of shelter. [s.1.]: MIT - Massachusetts Institute

SIMÃO, F. L. R. Ser mulher, "uma missão": Escola Superior de Ciências Domésticas, domesticidade, discurso e representações de gênero (1948-1992). Tese (Doutorado em História), - Universidade Federal de Juiz de Fora, 2016.

UNITED STATES GOVERNEMENT. Act of July 2, (Morrill Act), Public Law 37-108, which established land grant colleges, 07/02/1862; Enrolled Acts and Resolutions of Congress, 1789-1996. 1862. 